\title{
Association Between Variants of Neuromedin U Gene and Taste Thresholds and Food Preferences in European Children Results From the IDEFICS Study
}

Grippi, Claudio; Ahrens, Wolfgang; Buchecker, Kirsten; Chadjigeorgiou, Charalambos; De Henauw, Stefaan; Koni, Anna C.; Foraita, Ronja; Lissner, Lauren; Molnar, Dénes; Moreno, Luis Alberto; Pitsiladis, Yannis; Reisch, Lucia A.; Russo, Paola; Siani, Alfonso; Veidebaum, Toomas; lacoviello, Licia; Gianfagna, Francesco

Document Version

Accepted author manuscript

Published in:

Appetite

DOI:

10.1016/j.appet.2019.104376

Publication date:

2019

License

CC BY-NC-ND

Citation for published version (APA):

Grippi, C., Ahrens, W., Buchecker, K., Chadjigeorgiou, C., De Henauw, S., Koni, A. C., Foraita, R., Lissner, L., Molnar, D., Moreno, L. A., Pitsiladis, Y., Reisch, L. A., Russo, P., Siani, A., Veidebaum, T., lacoviello, L., \& Gianfagna, F. (2019). Association Between Variants of Neuromedin U Gene and Taste Thresholds and Food Preferences in European Children: Results From the IDEFICS Study. Appetite, 142, [104376]. https://doi.org/10.1016/j.appet.2019.104376

Link to publication in CBS Research Portal 


\section{Association Between Variants of Neuromedin U Gene and Taste Thresholds and Food Preferences in European Children: Results From the IDEFICS Study}

Claudio Grippi, Wolfgang Ahrens, Kirsten Buchecker, Charalambos Chadjigeorgiou, Stefaan De Henauw, Anna C. Koni, Ronja Foraita, Lauren Lissner, Dénes Molnar, Luis Alberto Moreno, Yannis Pitsiladis, Lucia A. Reisch, Paola Russo, Alfonso Siani, Toomas Veidebaum, Licia lacoviello, and Francesco Gianfagna Journal article (Accepted manuscript*)

\section{Please cite this article as:}

Grippi, C., Ahrens, W., Buchecker, K., Chadjigeorgiou, C., De Henauw, S., Koni, A. C., Foraita, R., Lissner, L., Molnar, D., Moreno, L. A., Pitsiladis, Y., Reisch, L. A., Russo, P., Siani, A., Veidebaum, T., lacoviello, L., \& Gianfagna, F. (2019). Association Between Variants of Neuromedin U Gene and Taste Thresholds and Food Preferences in European Children: Results From the IDEFICS Study. Appetite, 142, [104376]. https://doi.org/10.1016/j.appet.2019.104376

DOI: https://doi.org/10.1016/j.appet.2019.104376

* This version of the article has been accepted for publication and undergone full peer review but has not been through the copyediting, typesetting, pagination and proofreading process, which may lead to differences between this version and the publisher's final version AKA Version of Record.

Uploaded to CBS Research Portal: August २०२०

(C) 2019. This manuscript version is made available under the CC-BY-NC-ND 4.0 license http://creativecommons.org/licenses/by-nc-nd/4.0/ 
1 Association between variants of neuromedin $U$ gene and taste thresholds and food preferences

2 in European children:

3

4

5

6 Claudio Grippi ${ }^{\text {a, }}$, Wolfgang Ahrens ${ }^{\text {b,c }}$, Kirsten Buchecker ${ }^{\mathrm{d}}$, Charalambos Chadjigeorgiou ${ }^{\mathrm{e}}$, Stefaan

7 De Henauw ${ }^{\mathrm{f}}$, Anna C. Koni ${ }^{\mathrm{g}}$, Ronja Foraita ${ }^{\mathrm{b}}$, Lauren Lissner ${ }^{\mathrm{h}}$, Denés Molnár ${ }^{\mathrm{i}}$, Luis A. Moreno ${ }^{\mathrm{j}}$,

8 Yannis Pitsiladis k, Lucia A. Reisch ${ }^{1}$, Paola Russo ${ }^{\mathrm{m}}$, Alfonso Siani ${ }^{\mathrm{m}}$, Toomas Veidebaum ${ }^{\mathrm{n}}$, Licia

9 Iacoviello ${ }^{\mathrm{a}, \mathrm{o},{ }^{*}, \text { Francesco Gianfagna }}{ }^{\mathrm{o}, \mathrm{p}}$

\section{Results from the IDEFICS study}

a Department of Epidemiology and Prevention, IRCCS Istituto Neurologico Mediterraneo

NEUROMED, Pozzilli (IS), Italy;

${ }^{\mathrm{b}}$ Leibniz Institute for Prevention Research and Epidemiology - BIPS, Bremen, Germany.

${ }^{\mathrm{c}}$ Faculty of Mathematics and Computer Science, University of Bremen, Bremen, Germany.

${ }^{\mathrm{d}}$ Department of Food Science, TTZ, Bremerhaven, Germany.

${ }^{\mathrm{e}}$ Research and Education Foundation of Child Health, Strovolos, Cyprus.

${ }^{\mathrm{f}}$ Department of Public Health, Faculty of Medicine and Health Sciences, Ghent University, Ghent, Belgium.

g School of Life Sciences, College of Medical, Veterinary and Life Sciences, University of Glasgow, Glasgow, United Kingdom.

${ }^{\mathrm{h}}$ Section for Epidemiology and Social Medicine, University of Gothenburg, Göteborg, Sweden

${ }^{\text {i }}$ Department of Paediatrics, Medical School, University of Pécs, Pécs, Hungary.

${ }^{\mathrm{j}}$ GENUD (Growth, Exercise, Nutrition and Development) Research Group, University of Zaragoza, Zaragoza, Spain.

${ }^{\mathrm{k}}$ Collaborating Centre of Sports Medicine, University of Brighton, Brighton, United Kingdom. 
1 Department of Management, Society and Communication, Copenhagen Business School, 27 Copenhagen, Denmark.

$28{ }^{m}$ Unit of Epidemiology \& Population Genetics, Institute of Food Sciences, CNR, Avellino, Italy.

$29{ }^{\mathrm{n}}$ Department of Chronic Diseases, National Institute for Health Development, Tallinn, Estonia.

$30{ }^{\circ}$ EPIMED Research Center, Department of Medicine and Surgery, University of Insubria, Varese, 31 Italy

32 p Mediterranea Cardiocentro, Napoli, Italy

*Address correspondence to: Licia Iacoviello, MD, PhD - Department of Epidemiology and 36 Prevention, IRCCS Istituto Neurologico Mediterraneo Neuromed, Via dell'Elettronica - 86077 37 Pozzilli (IS), Italy. E-mail: licia.iacoviello@moli-sani.org Tel: +39-0865915246 Fax: +39 38 0865927575

Declarations of interest: none 
ABSTRACT (max 280 words- Appetite)

51 52

\begin{abstract}
Aim: The neuropeptide neuromedin U (NMU) known for its role in appetite, feeding and energy balance could be involved in the control of food choice and taste sensitivity. We examined the association between $N M U$ polymorphisms/haplotypes and taste thresholds and food preferences in a population of European children.
\end{abstract}

Methods: A total of 578 subjects from the IDEFICS study (mean age $7.5 \pm 0.8$ SD, boys $53.6 \%$ ) with $N M U$ genotype data and food preference (salty, fatty, sweet, flavour and umami food) and taste threshold (salt, fat, sweet, umami) tests available were analysed. Three single nucleotide polymorphisms (SNPs; rs6827359, T:C; rs12500837, T:C; rs9999653, C:T) of $N M U$ gene were analyzed and five major haplotypes were inferred. The associations between genotypes and food preferences or taste thresholds were investigated (odds ratios $-\mathrm{OR}$, adjusted for age, sex and country). A $p<0.05$ after false discovery rate adjustment ( $p$ FDR) was considered statistically significant.

Results: The association between $N M U$ genotypes and food preference showed two NMU SNPs associated with preference for food containing sodium glutamate (umami taste; rs6827359C, $\mathrm{OR}=1.61,95 \%$ confidence interval (CI):1.20-2.17; rs9999653T, OR=1.59, 95\%CI:1.18-2.13). In the 68 haplotype analysis, the CTT haplotype showed an OR of 1.70 (95\%CI:1.16-2.5) for the umami food 69 preference, while CCT haplotype showed an OR of 1.63 (95\%CI:1.11-2.40), compared to the most 70 frequent haplotype (TTC). Carriers of CCT/CCT vs subjects with no CCT haplotype showed an OR 71 of 4.78 (95\%CI:1.86-12.30). Umami food preference was associated with low values of BMI $z$ 72 score, arm circumferences, skinfolds and fat mass $(p F D R<0.05)$. No association between $N M U$ 73 genetic variants and taste thresholds was found. 
74 Conclusions: This study shows for the first time in children an association between preference for 75 umami food and a $N M U$ haplotype, previously found associated with low BMI values.

77 Keywords: food preferences; umami; neuromedin U; neurology; genetics; obesity 
INTRODUCTION

Taste sensing influences food preference, appetite and satiety, thereby regulating diet quality and total food intake and, as a result, weight maintenance (Dotson 2012). Five taste qualities can be perceived by humans: sweet, salty, bitter, sour and umami. The ability of discriminate between tastes has shown to be the result of evolution, to avoid hazardous compounds while searching for nutrients important for life and development.

In children, food preferences are often guided by taste alone. Specifically, preferences for sugar and fat may be acquired early in life, as children learn to prefer those flavors that are associated with high energy density and fat content, with higher risk of developing overweight (Drewnowski 1997). In line with that, several studies showed that food preferences and taste sensitivity differ between obese and non-obese children (Overberg 2012; Wardle 2001).

The mechanisms behind the regulation of food preferences and taste perception has only been partially revealed (MacLean 2017). Recent findings suggested that genetics plays an important role, since high heritability levels were found for both food preferences and taste perception 98 (Tornwall 2015). Genetic studies of taste variability have focused on a number of candidate genes encoding the taste receptors, hormones and neuropeptides, such as leptin, GLP-1 and NPY, important modulators at both peripheral and central level (Feeney 2011; Loper 2015).

Neuromedin U (NMU) is a neuropeptide with a highly conserved genetic structure, thought to have several important functions. Transgenic mouse models and experimental studies showed its main involvement in the regulation of body weight, through its effect on appetite, feeding and energy balance (Martinez 2015). Recently, an increased preference for obesogenic food was observed in rats knockdown for NMU Receptor 2 (NMUR2), the NMU receptor mainly expressed in the central nervous system (Benzon 2014). Although the effects of NMU are well understood in animal models, little is known about its role in humans besides a suggested role in adiposity 
regulation from epidemiological evidence. A rare NMU variant was in fact associated with

\section{MATERIALS AND METHODS}

\section{Study population}

IDEFICS (Identification and prevention of dietary - and lifestyle - induced health effects in children and infants) is a large European multi-center study aimed at investigating risk factors associated with childhood obesity (Ahrens 2011). A cohort of 16,229 children aged 2.0-9.9 years was recruited in a population-based survey between September 2007 and May 2008 (T0), in eight European countries (Belgium, Cyprus, Estonia, Germany, Hungary, Italy, Spain and Sweden).

For taste threshold and food preference test, from the subgroup of participating primary schoolchildren aged 6-9 or 7-9 years (depending on age of school enrolment), a subsample of 1839 (20.8\%) children were randomly selected (Lanfer 2012). For genetic analyses, a subgroup of 4,678 (28.8\%) samples was randomly selected from the total study population of European descent 
children, stratifying by age, sex and country (about 600 subjects from each country) (Gianfagna

\section{Data collection}

Food preference test. The preference test was organized as paired and forced choice on a board as previously described (Lanfer 2012, Knof 2011). Briefly, participating children had their last meal $1 \mathrm{~h}$ before to ensure that they were neither hungry nor sated. The test was conducted using five preference tests for five tastes. To evaluate sweet preference apple, juice was administered in small cups with a volume of $30 \mathrm{ml}$ at $18 \pm 2{ }^{\circ} \mathrm{C}$ and with different addition of sucrose (0.53-3.11\%). For the evaluation of flavour preferences, $0.05 \%$ apple flavour (nature identical, Sensient Flavors, Bremen, Germany) was added to the basic recipe. The children had to rinse their mouths with water between each pair sequence of the test. To assess the preference for salty, fatty and umami tastes, crackers were selected as food sample. The crackers were covered with $0.5 \%$ aqueous solution of sodium hydroxide (soda lye, Carl Roth Chemicals, Karlsruhe, Germany) to make them tastier to the children. The basic recipe of cracker included water, flour (wheat), fat (8\%) and salt. The same type of crackers was modified with an increased $8 \%$ of fat to assess high-fat preference, an increased $1 \%$ of salt for salty taste and monosodium glutamate (1\%) for umami crackers. In each sequence, the 
children had to choose their preferred food sample between the basic recipe and a modified one.

The order of assessment for the food choice was fat, salt and umami. The test procedure was subject to pre-testing before the beginning of the study (Suling 2011) and yielded reliable results in a reproducibility study (Knof 2011).

Taste detection threshold test. As a measure of taste sensitivity, detection threshold is the lowest value of a tastant that must be exceeded to have any effect on the observer. The procedure to evaluate the taste threshold was described in detail in Knof et al. (2011). In brief, a paired comparison test with five different watery solutions at different concentrations of tastants was served to the children in small cups of $20 \mathrm{ml}$. The concentration ranges of the tastants were sucrose (8.8-46.7 mmol/1), sodium chloride (3.4-27.4 mmol/1), caffeine $(0.26-1.3 \mathrm{mmol} / \mathrm{l})$ and monosodium glutamate (MSG) (0.6-9.5 mmol/1). The paired test was prepared as a board game and the children had to compare each test solution at increasing concentrations of tastants with a cup containing pure water, to find the cups that would taste differently from the previous one. Taste detection at lower $\underline{\text { tastant concentration (lower detection threshold value) indicates increased sensitivity for a specific }}$ tastant. Between the taste modalities, the children had to neutralize their taste with distilled water.

Anthropometric data. Height was measured using a standard clinical Seca 225 stadiometer (Seca, Hamburg, Germany) to the nearest $0.1 \mathrm{~cm}$, and weight was measured using a scale (BC 420 SMA; Tanita, Amsterdam, The Netherlands) to the nearest $0.1 \mathrm{~kg}$, on children wearing underwear clothes and without shoes. BMI was calculated as weight $(\mathrm{kg}) / \mathrm{height}(\mathrm{m})^{2}$. Waist and hip circumference was measured with an inelastic tape (Seca 200, precision $0.1 \mathrm{~cm}$, range $0-150 \mathrm{~cm}$ ). Age- and sex-specific BMI and waist circumference $z$-scores and BMI categories were calculated according to the criteria of the International Obesity Task Force (IOTF) (Cole 2012). Leg-to-leg impedance was measured with the Tanita scale and fat-free mass was calculated using the formula of Tyrrell et al (2001). Skinfold thicknesses (tricipital and subscapular) were measured with a Holtain caliper (Holtain, Holtain Ltd, Pembrokeshire, UK, range $0 \pm 40 \mathrm{~mm}$ ), taking measures twice on the right hand body side and using the mean of the two measures for the analyses. All 
measurements were collected by standardized protocols across centers, checking intra- and interobserver reliability (Stomfai 2011).

Genotyping. DNA extraction was carried out from saliva samples (Oragene DNA SelfCollection Kit, OG-300/OG-250; DNA Genotek Inc., Kanata, Ontario, Canada) (Koni 2011). Among the three main blocks of the NMU gene (chr4, 55595229-55636698, GRCh38.p7 assembly), three tag SNPs (rs6827359, rs12500837, rs9999653; intronic regions) were selected from the Caucasian HapMap Project data using the Tagger Pairwise method of Haploview software (version 4.1; Broad Institute, Cambridge, MA, USA) (Barrett 2005). Tag SNP selection criteria were described in Gianfagna et al (2017). The SNPs were genotyped by a multiplexed end-point assay. The allelic discrimination was performed by 7500 Fast Real-Time System (Applied Biosystems). The genotyping success rate was on average $97.6 \%$ and a randomly selected sample (5\%) was newly genotyped for all SNPs with $100 \%$ concordance.

\section{Statistical analysis}

The analyses were conducted with SAS (v9.3, SAS Institute Inc., Cary, NC) and R (v3.2.1; https://www.R-project.org/) software. Distribution of continuous variables was assessed using the Kolmogorov-Smirnov test and log-transformed variables were used where appropriate. HardyWeinberg equilibrium (HWE) was assessed with the chi-square test. The best genetic model was checked for each genotype-phenotype association, testing dominance deviation from additivity and considering the additive model as default (Hoffman 2004). The Haplo.stats package of R software was used to estimate the haplotype frequencies and to verify the associations between haplotype and phenotype (haplo.glm function, the most prevalent haplotype as reference). Haplotypes with frequencies lower than 1\% were excluded. Multiple regression analyses were performed using age, sex and countries as covariates, to evaluate the association between genotypes and food preferences (basic food or modified food with salty, fatty, umami, sweet and flavor tastes) or taste thresholds (sweet, salty, umami, bitter). The Benjamini-Hochberg false discovery rate (FDR) (Benjamini 
1995) was used to adjust the results for multiple comparisons, using PROC MULTTEST in SAS. A

FDR-adjusted $p$ value $(p$ FDR $)<0.05$ was considered as statistically significant.

\section{RESULTS}

\section{Population characteristics}

Characteristics of the study population are shown in Table 1. Children with at least one SNP successfully genotyped in NMU gene and eating behavior data available were 578 (mean age 7.5 $\pm 0.8 \mathrm{SD}$, boys $53.6 \%$ ). The lowest taste threshold value was found for sweet taste, taking into account mean thresholds and concentration ranges of test solutions (sucrose, $19.9 \mathrm{mmol} / \mathrm{l}$; range 8.8-46.7). In food preference tests, the most appreciated food were salt-added crackers $(63.7 \%$ of children preferred them to the basic recipe crackers), while sodium glutamate-added crackers (umami taste) were the less appreciated (33.4\%). Genotype frequencies are reported in Table 2a. No statistically significant differences were found between genotype frequencies of children randomly selected to be included or excluded from this analysis subjects (data not shown). All genotypes were in Hardy-Weinberg equilibrium and the minor allele frequencies (MAF) were similar to values reported in the HapMap database for Caucasians. Six haplotypes were inferred (Table 2b; wild-type haplotype $43.9 \%$ ).

\section{Associations with food preferences and taste thresholds}

Deviation from additivity test showed codominance as the best genetic model for all phenotype-SNP and phenotype-haplotype associations, except for umami food preference for the reference haplotype TTC (H7), that showed a dominant model. 
The analysis of the association between NMU genetic variants and food preferences are

shown in Table 3. Children carrying mutant allele in Two-two out of the three NMU SNPs studied were more likely to prefer associated with preference for food containing sodium glutamate (umami taste) with respect to the same food prepared with a basic recipe (; rs6827359, odds ratio $\mathrm{OR}=1.61,95 \%$ confidence interval $-95 \% \mathrm{CI}: 1.20-2.17 ;$ rs9999653, OR=1.59, 95\%CI:1.18-2.13; Table 3). The haplotype analysis confirmed the association between genetic variants and preference for with-umami preferencefood. Subjects carrying the CTT haplotype showed an OR of 1.70 (95\%CI:1.16-2.50) for the umami preference, while CCT haplotype showed an OR of 1.63 (95\%CI:1.11-2.40), as compared to the most frequent TTC haplotype. The reference haplotype showed a reduced odd for umami preference when compared to all other haplotypes $(\mathrm{OR}=0.42$; 95\%CI:0.27-0.66). The association between umami food preference and the two SNPs as well as the TTC haplotype remained statistically significant after FDR correction. The same analysis considering each single genotype or haplotype versus the correspondent wild-type (Table 3 , last rows) showed even higher association values. Homozygotes for mutant allele of rs6827359 $(\mathrm{OR}=2.57 ; 95 \% \mathrm{CI}: 1.43-4.61)$ and of rs9999653 (OR=2.31; 95\%CI:1.29-4.15) versus the opposite homozygotes showed FDR-significant association with umami food preference. Similarly, homozygotes for CTT $(\mathrm{OR}=4.78 ; 95 \% \mathrm{CI}: 1.86-12.30)$, as well as carriers of $\mathrm{TTC}(\mathrm{OR}=0.43$; 95\%CI:0.26-0.68) haplotype showed FDR-significant association with umami food preference when compared with subjects without that specific haplotype. No significant associations were found between $N M U$ genotypes or haplotypes and the other food preferences (Suppl. Table 1).

The analysis of the association between $N M U$ genetic variants and taste thresholds showed no significant results (Table 4, codominant model, and Suppl. Table 2, genotype or haplotype contrasts).

\section{Association between umami preference and adiposity indices}


Preference for umami food was associated with lower levels of the main anthropometric

\section{DISCUSSION}

In this study, conducted in a sub-sample of children from the large European IDEFICS cohort, we found variants (two SNPs and two haplotypes) of $N M U$ gene associated with preference for food containing glutamate. Preference for umami food was inversely associated with several anthropometric parameters such as BMI, weight, waist and arm circumference, skinfolds and fat mass.

This is the first study in humans investigating the potential involvement of NMU in influencing food preferences and taste perception in humans, although some experimental studies suggested this potential role. A recent experimental study in rats revealed that NMUR2, one of the two NMU receptors, could induce preference for high-fat foods (Benzon 2014). The NMUR2 is located mainly in central nervous system and is highly expressed in the hypothalamous and in other regions receiving fibers from taste sensory ganglia (Stanska 2016; Li 2017). Our results on the association between NMU genetic variants and umami food preference support the role of NMU in 
regulating feeding behavior (Jethwa 2005; Kowalski 2005), specifically in neuronal pathways of

taste-like/dislike preferences for umami food. We found no association with other food preferences. In line with our negative findings, a recent experimental study in mice showed that a NMU analog has no effect on preference for a sweet drink (Kaisho 2017). Although several hormones and neuropeptides were suggested as modulators of peripheral gustatory system (Loper 2015), we found no association between $N M U$ genetic variants and taste perception thresholds. The reason of this negative result could be a lack of expression of NMU receptors in oral cavity. In fact, we found no literature data on expression of NMUR1 and NMUR2 in oral cavity, although at least NMUR1 is abundantly present along the gastrointestinal tract (Li 2017; Hedrick 2000; Raddatz 2000). These findings confirm that the associations of NMU with food preference is mediated by central nervous and not peripheral gustatory system.

In our population, we found significant associations between umami preference and anthropometric parameters. Although some associations did not reach statistical significance, all were concordantly in the direction of a protective effect for umami preference. The strongest significant association was found for fat mass. Children with preference for umami food present a decreased fat mass of approximately $1 \mathrm{~kg}$. The umami taste is the fifth taste identified (Ikeda 2002), induced principally by three molecules: monosodium glutamate (MSG), inosine-5'-monophosphate (IMP) and guanylo-5'-monophosphate (GMP). These substances enhance the savory of foods and cause sensation such as pleasure and satisfaction (De Araujo 2003; Kurihara 2015), as well as insulin release, salivary, gastric and pancreatic secretion, gastric emptying and distal colon peristalsis (Stanska 2016). These effects could result in the modulation of short-term intake and satiety by giving umami an important role in appetite control (Masic 2014). The variants found associated with an increased preference for umami food were the same identified associated with lower BMI values, in a larger sample of the same population (Gianfagna 2017), suggesting that an increase in food preferences for umami could be also associated with decreased BMI. Supporting this hypothesis, a study in rats showed an association between preference of monosodium glutamate 
solution and reduction of obesity (Kondoh 2008). This may suggest a potential mediating effect of umami food preference in the association between $N M U$ genetic variants and BMI. However, in the subgroup with food preference data available, the association between $N M U$ variants and BMI was not significant as we previously reported in the whole sample with genetic data available (Gianfagna 2013) due to the smaller sample size. The regression coefficient was however similar.

The strength of this study is the availability of a children population, which represent a good model for genetic studies. In fact, since the environment has had less time to exert its effect, phenotypes have a larger genetic component than in adults. However, taste and food preferences are influenced by several non-genetic factors, such as social, community and environmental factors, operating at multiple levels throughout life (Beckerman 2017; Russell 2013), which were not considered in this analysis. Although a confounding effect should be excluded due to the genetic study design, we cannot exclude a modification of the genetic effect due to factors not considered in the analyses. A further limitation of this study is the sample size, which is underpowered for the mediation effect analysis of umami preferences.

In conclusion, variants in the $N M U$ gene might play a role in determining umami food preferences. This mechanism could mediate part of the association between the same $N M U$ genetic variants and BMI, previously observed, although further studies are necessary to confirm this hypothesis. 


\section{Acknowledgements}

This study was conducted as part of the IDEFICS study (http://www.idefics.eu). We are grateful for the support provided by school boards, headmasters and communities. We thank the IDEFICS children and their parents for participating in this extensive examination. This study was supported by the European Community within the Sixth RTD Framework Programme Contract no. 016181 (FOOD). This analysis was partially supported by the Fondazione Veronesi (2014 Young Investigator Research Programme award to FG) and the Italian Ministry of Health 2011 (grant number 167/GR-2011-02351736 to FG). We thank Daniela Cugino and Iolanda Santimone for samples genotyping at the Fondazione Giovanni Paolo II, Campobasso, Italy. 


\section{REFERENCES}

Ahrens, W., Bammann, K., Siani, A., Buchecker, K., De Henauw, S., Iacoviello, L., Hebestreit, A., Krogh, V., Lissner, L., Mårild, S., Molnár, D., Moreno, L.A., Pitsiladis, Y.P., Reisch, L., Tornaritis, M., Veidebaum, T., Pigeot, I. (2011). IDEFICS Consortium. The IDEFICS cohort: design, characteristics and participation in the baseline survey. International Journal of Obesity, 35, 3-15.

Barrett, J.C., Fry, B., Maller, J., Daly, M.J. (2005). Haploview: analysis and visualization of LD and haplotype maps. Bioinformatics, 21, 263-265.

Beckerman, J.P., Alike, Q., Lovin, E., Tamez, M., Mattei, J. (2017). The Development and Public Health Implications of Food Preferences in Children. Frontiers in Nutrition, 4, 66.

Benjamini, Y., Hochberg, Y. (1995). Controlling the False Discovery Rate: A Practical and Powerful Approach to Multiple Testing. Journal of the Royal Statistical Society, 57, 289-300.

Benzon, C.R., Johnson, S.B., McCue, D.L., Li, D., Green, T.A., Hommel, J.D. (2014). Neuromedin $U$ receptor 2 knockdown in the paraventricular nucleus modifies behavioral responses to obesogenic high-fat food and leads to increased body weight. Neuroscience, 258, 270-9.

Cole, T.,J., Lobstein, T. (2012). Extended international (IOTF) body mass index cut-offs for thinness, overweight and obesity. Pediatric Obesity, 7, 284-294.

Cugino, D., Gianfagna, F., Ahrens, W., De Henauw, S., Koni, A.C., Marild, S., Molnar, D., Moreno, L.A., Pitsiladis, Y., Russo, P., Siani, A., Tornaritis, M., Veidebaum, T., Iacoviello, L. (2013). Polymorphisms of matrix metalloproteinase gene and adiposity indices in European children: results of the IDEFICS study. International Journal of Obesity, 37, 1539-1544.

De Araujo, I.E., Kringelbach, M.L., Rolls, E.T., Hobden, P. (2003). Representation of umami taste in the human brain. Journal of Neurophysiology, 90, 313-319. 
Dotson, C.D., Colbert, C.L., Garcea, M., Smith, J.C., Spector, A.C. (2012). The

consequences of gustatory deafferentation on body mass and feeding patterns in the rat. American Journal of Physiology. Regulatory, Integrative and Comparative Physiology, 303:R611-623.

Drewnowski, A. (1997). Taste preferences and food intake. Annual Review of Nutrition, 17, 237-253.

Feeney, E., O'Brien, S., Scannell, A., Markey, A., Gibney, E.R. (2011). Genetic variation in taste perception: does it have a role in healthy eating? Proceedings of the Nutrition Society, 70 (1), $135-143$

Gianfagna, F., Cugino, D., Ahrens, W., Bailey, M.E., Bammann, K., Herrmann, D., Koni, A.C., Kourides, Y., Marild, S., Molnár, D., Moreno, L.A., Pitsiladis, Y.P., Russo, P., Siani, A., Sieri, S., Sioen, I., Veidebaum, T., Iacoviello, L. (2013). Understanding the links among neuromedin U gene, beta2-adrenoceptor gene and bone health: an observational study in European children. PLoS One, 8, e70632.

Gianfagna, F., Grippi, C., Ahrens, W., Bailey, M.E., Börnhorst, C., De Henauw, S., Foraita, R., Koni, A.C., Krogh, V., Mårild, S., Molnár, D., Moreno, L., Pitsiladis, Y., Russo, P., Siani, A., Tornaritis, M., Veidebaum, T., Iacoviello, L. (2017). The role of neuromedin U in adiposity regulation. Haplotype analysis in European children from the IDEFICS Cohort. PLoS One, 12, $\mathrm{e} 0172698$

Hainerová, I., Torekov, S.S., Ek, J., Finková, M., Borch-Johnsen, K., Jørgensen, T., Madsen, O.D., Lebl, J., Hansen, T., Pedersen, O. (2006). Association between neuromedin U gene variants and overweight and obesity. The Journal of Clinical Endocrinology \& Metabolism, 91, 5057-5063.

Hedrick, J.A., Morse, K., Shan, L.X., Qiao, X.D., Pang, L., Wang, S., Laz, T., Gustafson, E.L., Bayne, M., Monsma, F.J. (2000). Identification of a human gastrointestinal tract and immune system receptor for the peptide neuromedin U. Molecular Pharmacology, 58, 870-875. 
Hoffman, K., Schulze, M.B., Schienkiewitz, A., Nöthlings, U., Boeing, H. (2004).

Application of a new statistical method to derive dietary patterns in nutrition epidemiology. American Journal of Epidemiology, 159, 935-944.

Ikeda, K. (2002). New Seasonings. Chemical Senses, 27, 847-849.

Jethwa, P.H., Small, C.J., Smith, K.L., Seth, A., Darch, S.J., Abbott, C.R., Murphy, K.G., Todd, J.F., Ghatei, M.A., Bloom, S.R. (2005). Neuromedin U has a physiological role in the regulation of food intake and partially mediates the effects of leptin. American Journal of Physiology Endocrinology and Metabolism, 289, E301-305.

Kaisho, T., Nagai, H., Asakawa, T., Suzuki, N., Fujita, H., Matsumiya, K., Nishizawa, N., Kanematsu-Yamaki, Y., Dote, K., Sakamoto, J.I., Asami, T., Takekawa, S. (2017). Effects of peripheral administration of a Neuromedin $U$ receptor 2-selective agonist on food intake and body weight in obese mice. International Journal of Obesity, 41, 1790-1797.

Kamisoyama, H., Honda, K., Saneyasu, T., Sugahara, K., Hasegawa, S. (2007). Central administration of neuromedin U suppresses food intake in chicks. Neuroscience Letters, 420, 1-5.

Knof, K., Lanfer, A., Bildstein, M.O., Buchecker, K., Hilz, H. (2011). IDEFICS Consortium. Development of a method to measure sensory perception in children at the European level. International Journal of Obesity, 35(Suppl 1), S131-136.

Kondoh, T., Torii, K. (2008). MSG intake suppresses weight gain, fat deposition, and plasma leptin levels in male Sprague-Dawley rats. Physiology \& Behavior, 95, 135-144.

Koni, A.C., Scott, R.A., Wang, G., Bailey, M.E., Peplies, J., Bammann, K., Pitsiladis, Y.P. (2011). DNA yield and quality of saliva samples and suitability for large-scale epidemiological studies in children. International Journal of Obesity, 35(Suppl 1), S113-118.

Kowalski, T.J., Spar, B.D., Markowitz, L., Maguire, M., Golovko, A., Yang, S., Farley, C., Cook, J.A., Tetzloff, G., Hoos, L., Del Vecchio, R.A., Kazdoba, T.M., McCool, M.F., Hwa, J.J., Hyde, L.A., Davis, H., Vassileva, G., Hedrick, J.A., Gustafson, E.L. (2005). Transgenic 
overexpression of neuromedin $U$ promotes leanness and hypophagia in mice. Journal of Endocrinology, 185, 151-164.

Kurihara, K. (2015). Umami the Fifth Basic Taste: History of Studies on Receptor Mechanisms and Role as a Food Flavor. BioMed Research International, 2015, 189402.

Lanfer, A., Knof, K., Barba, G., Veidebaum, T., Papoutsou, S., de Henauw, S., Soós, T., Moreno, L.A., Ahrens, W., Lissner, L. (2012). Taste preferences in association with dietary habits and weight status in European children: results from the IDEFICS study. International Journal of Obesity, 36, 27-34.

Li, X., Niu, M., Su, J., Ma, Z., Jin, M., Qiao, W., Zhang, Y., Feng, Y., An, N., Hou, Y., Yang, S., Chuan, S., Lei, Z. (2017). Cloning and expression patterns of neuromedin U and its receptors in pigs. Neuropeptides, 64, 47-60.

Loper, H.B., La Sala, M., Dotson, C., Steinle, N. (2015). Taste perception, associated hormonal modulation, and nutrient intake. Nutrition Reviews, 73, 83-91.

MacLean, P.S., Blundell, J.E., Mennella, J.A., Batterham, R.L. (2017). Biological control of appetite: A daunting complexity. Obesity (Silver Spring), 25(Suppl 1), S8-S16.

Martinez, V.G., O’Driscoll, L. (2015). Neuromedin U: a multifunctional neuropeptide with pleiotropic roles. Clinical Chemistry, 61, 471-482.

Masic, U., Yeomans, M.R. (2014). Umami flavor enhances appetite but also increases satiety. The American Journal of Clinical Nutrition, 100 (3), 532-538.

Overberg, J., Hummel, T., Krude, H., Wiegand, S. (2012). Differences in taste sensitivity between obese and non-obese children and adolescents. Archives of Disease in Childhood, 97, 1048-1052.

Russell, C.G., Worsley, A. (2013). Why don't they like that? And can I do anything about it? The nature and correlates of parents' attributions and self-efficacy beliefs about preschool children's food preferences. Appetite, 66, 34-43. 
Stańska, K., Krzeski, A. (2016). The umami taste: from discovery to clinical use. Polish Journal of Otolaryngology, 70 (4), 10-15.

Stomfai, S., Ahrens, W., Bammann, K., Kova'cs, E., Mårild, S., Michels, N., Moreno, L.A., Pohlabeln, H., Siani, A., Tornaritis, M., Veidebaum, T., Molnár, D.; IDEFICS Consortium. (2011) Intra- and inter-observer reliability in anthropometric measurements in children. International Journal of Obesity (London), 35 Suppl 1, S45-51.

Suling, M., Hebestreit, A., Peplies, J., Bammann, K., Nappo, A., Eiben, G., Alvira, J.M., Verbestel, V., Kovács, E., Pitsiladis, Y.P., Veidebaum, T., Hadjigeorgiou, C., Knof, K., Ahrens, W. (2011). Design and results of the pretest of the IDEFICS study. International Journal of Obesity, 35, (Suppl 1), S30-44.

Tyrrell, V.J., Richards, G., Hofman, P., Gillies, G.F., Robinson, E., Cutfield, W.S. (2001) Foot-to-foot bioelectrical impedance analysis: a valuable tool for the measurement of body composition in children. International Journal of Obesity and Related Metabolic Disorders, 25, 273-278.

Törnwall, O., Silventoinen, K., Hiekkalinna, T., Perola, M., Tuorila, H., Kaprio, J. (2014). Identifying flavor preference subgroups. Genetic basis and related eating behavior traits. Appetite, $75,1-10$.

Wardle, J., Guthrie, C., Sanderson, S., Birch, L., Plomin, R. (2001). Food and activity preferences in children of lean and obese parents. International Journal of Obesity and Related Metabolic Disorders, 25, 971-977. 
Table 1. Anthropometric characteristics of $\mathrm{N}=578$ children with genotype and food preferences or taste threshold data available.

\begin{tabular}{|c|c|c|}
\hline Variables & $\mathbf{N}$ & $\begin{array}{c}\text { Mean } \pm \text { SD } \\
\text { n (\%) }\end{array}$ \\
\hline Age (years; mean $\pm \mathrm{SD}$ ) & 578 & $7.5 \pm 0.8$ \\
\hline Males (n, \%) & 578 & $310(53.6 \%)$ \\
\hline Body Mass Index (mean \pm SD) & 578 & $16.8 \pm 2.7$ \\
\hline BMI $z$-score $($ mean $\pm \mathrm{SD})$ & 578 & $0.47 \pm 1.17$ \\
\hline Weight $(\mathrm{kg} ;$ mean $\pm \mathrm{SD})$ & 578 & $27.3 \pm 6.1$ \\
\hline Waist circumference (cm; mean \pm SD) & 578 & $57.0 \pm 7.0$ \\
\hline Hip Circumference (cm; mean \pm SD) & 577 & $67.1 \pm 6.7$ \\
\hline Waist to hip (mean \pm SD) & 577 & $0.85 \pm 0.05$ \\
\hline Arm circumference $(\mathrm{cm} ;$ mean $\pm \mathrm{SD})$ & 572 & $19.7 \pm 2.5$ \\
\hline Skinfolds (sum of tricipital and subscapular, mm; mean $\pm \mathrm{SD}$ ) & 570 & $19.1 \pm 8.1$ \\
\hline Fat mass $(\mathrm{kg} ;$ mean $\pm \mathrm{SD})$ & 569 & $8.1 \pm 3.8$ \\
\hline Overweight + obese & 578 & $135(23.4 \%)$ \\
\hline Obese & 578 & $49(8.5 \%)$ \\
\hline \multicolumn{3}{|l|}{ Children preferring each modified food versus basic recipe } \\
\hline Fat $(n, \%)$ & 460 & $258(56.1 \%)$ \\
\hline Salt (n,\%) & 466 & $297(63.7 \%)$ \\
\hline Umami (n,\%) & 461 & $154(33.4 \%)$ \\
\hline Sweet $(n, \%)$ & 514 & $300(58.4 \%)$ \\
\hline Flavour $(n, \%)$ & 518 & $304(58.7 \%)$ \\
\hline \multicolumn{3}{|l|}{ Taste detection thresholds } \\
\hline Sweet (sucrose $8.8-46.7 \mathrm{mmol} / \mathrm{l} ;$ mean $\pm \mathrm{SD}$ ) & 517 & $19.9 \pm 11.1$ \\
\hline Salty (sodium chloride $3.4-27.4 \mathrm{mmol} / \mathrm{l} ;$ mean $\pm \mathrm{SD}$ ) & 522 & $12.9 \pm 7.2$ \\
\hline Bitter (caffeine $0.26-1.3 \mathrm{mmol} / \mathrm{l}$; mean $\pm \mathrm{SD}$ ) & 521 & $0.88 \pm 0.49$ \\
\hline Umami (MSG 0.6-9.5 mmol/1; mean \pm SD) & 516 & $4.2 \pm 3.1$ \\
\hline
\end{tabular}


Table 2a. Allele frequencies and Hardy-Weinberg equilibrium of the Neuromedin U (NMU) single nucleotide polymorphisms $($ SNPs; $\mathrm{n}=578$ with at least one SNP successfully genotyped).

\begin{tabular}{|c|c|c|c|c|c|c|c|c|}
\hline SNP & $\begin{array}{c}\text { Major:minor } \\
\text { allele }\end{array}$ & $\mathbf{N}$ & $\begin{array}{l}\text { Homozygous } \\
\text { (major allele) }\end{array}$ & Heterozygous & $\begin{array}{l}\text { Homozygous } \\
\text { (minor allele) }\end{array}$ & $\begin{array}{c}\text { HWE* }^{*} \\
(p)\end{array}$ & $\begin{array}{l}\text { MAF* } \\
(\%)\end{array}$ & $\begin{array}{l}\text { CEU } \\
(\%)\end{array}$ \\
\hline rs6827359 & $\mathrm{T}^{*}: \mathrm{C}$ & 576 & $161(27.9 \%)$ & $268(46.5 \%)$ & $147(25.5 \%)$ & 0.11 & 49 & 40 \\
\hline rs12500837 & $\mathrm{T}^{*}: \mathrm{C}$ & 577 & $323(56.0 \%)$ & $216(37.4 \%)$ & $38(6.6 \%)$ & 0.91 & 24 & 21 \\
\hline rs9999653 & $\mathrm{C}: \mathrm{T}^{*}$ & 574 & $132(23.0 \%)$ & $264(46.0 \%)$ & $178(31.4 \%)$ & 0.42 & 54 & 49 \\
\hline
\end{tabular}

*Hardy-Weinberg Equilibrium (HWE) and Minor Allele Frequency (MAF) were checked on the whole sample of 4649 subjects genotyped; rs9999653T allele is considered the minor allele based on population frequencies; CEU=Utah Residents (Caucasians) with Northern and Western European Ancestry

Table 2b. Haplotype frequencies ( $n=578$ with at least one SNP successfully genotyped).

\begin{tabular}{|ccc|c|}
\hline rs6827359 & rs12500837 & rs9999653 & Freq (\%) \\
\hline $\mathrm{T}$ & $\mathrm{T}$ & $\mathrm{C}$ & $43.2 \%$ \\
\hline $\mathrm{T}$ & $\mathrm{T}$ & $\mathrm{T}$ & $7.9 \%$ \\
\hline $\mathrm{C}$ & $\mathrm{C}$ & $\mathrm{C}$ & $2.7 \%$ \\
\hline $\mathrm{C}$ & $\mathrm{C}$ & $\mathrm{T}$ & $22.6 \%$ \\
\hline $\mathrm{C}$ & $\mathrm{T}$ & $\mathrm{T}$ & $23.6 \%$ \\
\hline
\end{tabular}


Table 3. Odds ratios (OR) for preferring specific modified food to basic recipe, in children carrying genetic variants versus wild-type (codominant model, OR per minor allele).

\begin{tabular}{|c|c|c|c|c|c|c|c|}
\hline \multirow[b]{2}{*}{$\begin{array}{l}\text { Food } \\
\text { preferences }\end{array}$} & \multicolumn{3}{|c|}{$\begin{array}{c}\text { Genotypes } \\
\text { OR (95\%CI) }\end{array}$} & \multicolumn{4}{|c|}{$\begin{array}{c}\text { Haplotypes } \\
\text { OR (95\%CI) }\end{array}$} \\
\hline & $\operatorname{rs6827359}(\mathrm{C})$ & $\operatorname{rs} 12500837(C)$ & rs9999653 (T) & H2 (CCT) & H4 (CTT) & H8 (TTT) & H7 (TTC) $^{\circ}$ \\
\hline Fat & $1.04(0.79-1.36)$ & $0.91(0.67-1.25)$ & $1.07(0.82-1.40)$ & $0.98(0.70-1.38)$ & $1.10(0.77-1.56)$ & $0.94(0.57-1.57)$ & $1.00(0.76-1.31)$ \\
\hline Salt & $1.07(0.81-1.40)$ & $0.98(0.71-1.35)$ & $1.11(0.84-1.46)$ & $1.06(0.74-1.51)$ & $1.15(0.81-1.64)$ & $1.04(0.62-1.73)$ & $0.93(0.71-1.22)$ \\
\hline Sweet & $1.11(0.87-1.42)$ & $0.95(0.71-1.26)$ & $1.16(0.91-1.49)$ & $1.04(0.75-1.44)$ & $1.24(0.90-1.70)$ & $1.21(0.77-1.89)$ & $0.88(0.68-1.13)$ \\
\hline Flavour & $0.93(0.73-1.20)$ & $0.90(0.67-1.20)$ & $0.89(0.69-1.15)$ & $0.85(0.61-1.18)$ & $0.98(0.70-1.36)$ & $0.94(0.59-1.51)$ & $1.08(0.83-1.41)$ \\
\hline Umami & $1.61(1.20-2.17) *$ & $1.34(0.96-1.87)$ & $1.59(1.18-2.13) *$ & $1.63(1.11-2.40)$ & $1.70(1.16-2.50)$ & $1.38(0.78-2.42)$ & $0.42(0.27-0.66)^{*}$ \\
\hline$W / M v_{s} W / W_{\dagger}$ & $1.17(0.69-1.97)$ & $1.26(0.80-1.96)$ & $0.94(0.54-1.64)$ & $1.56(0.96-2.53)$ & $1.29(0.78-2.11)$ & $1.50(0.76-2.95)$ & $0.42(0.26-0.68) *$ \\
\hline$M / M v_{s} W / W \dagger$ & $2.57(1.43-4.61) *$ & $1.98(0.87-4.50)$ & $2.31(1.29-4.15) *$ & $2.92(1.17-7.33)$ & $4.78(1.86-12.30) *$ & $1.00(0.18-5.70)$ & $0.43(0.24-0.78)$ \\
\hline
\end{tabular}

Bold: nominally significant associations; *significant also after FDR correction, including rare haplotypes (not shown); § results for dominant model ${ }^{\circ}$ all other haplotypes as reference; $\dagger$ Genotype or haplotype contrasts: for genotype analysis, heterozygotes or homozygotes for variant alleles (M) vs homozygotes for wild-type allele (W, ref); for haplotype analysis, subjects with 1 (w/M) or two (M/M) copies of a specific haplotypes versus subjects with the most frequent haplotype (TTC). Analyses adjusted for age, sex, country 


\begin{tabular}{|c|c|c|c|c|c|c|c|}
\hline \multirow[b]{2}{*}{$\begin{array}{l}\text { Taste } \\
\text { thresholds }\end{array}$} & \multicolumn{3}{|c|}{$\begin{array}{c}\text { Genotypes } \\
(\text { beta } \pm \mathrm{SE}, p)\end{array}$} & \multicolumn{4}{|c|}{$\begin{array}{c}\text { Haplotypes } \\
(\text { beta } \pm \text { SE, } p)\end{array}$} \\
\hline & $\operatorname{rs6827359}(\mathrm{C})$ & $\operatorname{rs12500837(C)}$ & rs9999653 (T) & H2 (CCT) & H4 (CTT) & H8 (TTT) & H7 (TTC) $^{\circ}$ \\
\hline Sweet & $-0.34 \pm 0.65(0.60)$ & $-0.03 \pm 0.75(0.97)$ & $-0.90 \pm 0.64(0.16)$ & $-0.59 \pm 0.83(0.48)$ & $-0.79 \pm 0.84(0.35)$ & $-1.57 \pm 1.31(0.23)$ & $0.74 \pm 0.65(0.26)$ \\
\hline Salty & $0.37 \pm 0.42(0.38)$ & $0.59 \pm 0.49(0.23)$ & $-0.18 \pm 0.42(0.66)$ & $0.35 \pm 0.54(0.52)$ & $-0.15 \pm 0.55(0.78)$ & $-1.57 \pm 0.84(0.06)$ & $0.07 \pm 0.42(0.87)$ \\
\hline Bitter & $-0.02 \pm 0.03(0.51)$ & $0.02 \pm 0.03(0.63)$ & $-0.02 \pm 0.02(0.52)$ & $-0.004 \pm 0.04(0.92)$ & $-0.03 \pm 0.037(0.44)$ & $0.06 \pm 0.06(0.33)$ & $0.001 \pm 0.03(0.97)$ \\
\hline Umami & $-0.08 \pm 0.18(0.66)$ & $0.12 \pm 0.22(0.59)$ & $-0.14 \pm 0.19(0.46)$ & $0.002 \pm 0.24(0.99)$ & $-0.24 \pm 0.24(0.32)$ & $-0.08 \pm 0.38(0.83)$ & $0.10 \pm 0.19(0.61)$ \\
\hline
\end{tabular}

${ }^{\circ}$ All other haplotypes as reference. Analysis adjusted for age, sex and country. Lower detection threshold values indicate higher sensitivity for a specific tastant. 
Table 5. Associations between anthropometric variables and umami or NMU variants in the IDEFICS children population.

\begin{tabular}{|c|c|c|c|c|c|c|}
\hline \multirow[b]{2}{*}{ Anthropometric } & \multirow{2}{*}{$\begin{array}{l}\mathbf{N} \\
\mathbf{N}\end{array}$} & \multirow{2}{*}{$\begin{array}{c}\text { Model } 1 \\
\text { Umami preferences }\end{array}$} & \multicolumn{4}{|c|}{ Model 2} \\
\hline & & & Umami preferences & H2/H2 & H4/H4 & H8/H8 \\
\hline $\mathrm{BMI} z$-score $($ beta $\pm \mathrm{SE}, p)$ & 456 & $-0.25 \pm 0.12(0.034)^{* \circ}$ & $-0.23 \pm 0.12(0.043)^{\circ}$ & $-0.12 \pm 0.26(0.64)$ & $-0.15 \pm 0.23(0.52)$ & $0.22 \pm 0.60(0.71)$ \\
\hline Waist $z$-score (beta $\pm \mathrm{SE}, p$ ) & 456 & $-0.16 \pm 0.19(0.42)$ & $-0.12 \pm 0.19(0.53)$ & $-0.11 \pm 0.28(0.69)$ & $0.29 \pm 0.29(0.32)$ & $0.03 \pm 0.82(0.97)$ \\
\hline Arm circumference $($ beta $\pm \mathrm{SE}, p)$ & 450 & $-0.63 \pm 0.25(0.011)^{*}$ & $-0.58 \pm 0.23(0.011)^{*}$ & $-0.26 \pm 0.52(0.61)$ & $-0.41 \pm 0.44(0.36)$ & $0.61 \pm 1.34(0.65)$ \\
\hline Skinfolds ${ }^{\S}($ beta \pm SE, $p$ ) & 450 & $-1.75 \pm 0.78(0.025)^{*}$ & $-1.71 \pm 0.68(0.012)^{*}$ & $-0.53 \pm 1.49(0.72)$ & $0.05 \pm 1.45(0.98)$ & $-2.18 \pm 1.92(0.26)$ \\
\hline Fat mass (beta $\pm \mathrm{SE}, p)$ & 453 & $-0.93 \pm 0.37(0.012)^{*}$ & $-0.85 \pm 0.34(0.012)^{*}$ & $-0.21 \pm 0.77(0.78)$ & $-0.74 \pm 0.61(0.23)$ & $0.98 \pm 2.08(0.64)$ \\
\hline Overweight/obesity (OR, 95\%CI) & 456 & $0.70(0.42-1.17)$ & $0.72(0.44-1.19)$ & $1.09(0.40-2.98)$ & $0.80(0.29-2.16)$ & $0.96(0.09-10.66)$ \\
\hline
\end{tabular}

Model 1: age, sex and country; model 2: all in model 1 plus haplotypes. Bold: nominally significant associations; *significant also after FDR correction; ${ }^{\S}$ sum of tricipital and subscapular skinfolds; ${ }^{\circ}$ This is equal to $-6.1 \pm 3.0$ (beta \pm SE) BMI percentiles of the European population distribution (extended definition, Cole et al. 2012) Analysis adjusted for age, sex, country 
Supplementary Table 1. Associations between Neuromedin U genotypes and food preferences in the IDEFICS children population.

\begin{tabular}{|c|c|c|c|c|c|c|c|c|}
\hline \multirow[b]{2}{*}{$\begin{array}{l}\text { Food } \\
\text { preferences }\end{array}$} & \multirow[b]{2}{*}{$\begin{array}{l}\text { Genotvpe or } \\
\text { haplotype } \\
\text { contrast } \dagger\end{array}$} & \multicolumn{3}{|c|}{$\begin{array}{c}\text { Genotypes } \\
\text { OR (95\%CI) }\end{array}$} & \multicolumn{4}{|c|}{$\begin{array}{c}\text { Haplotypes } \\
\text { OR }(95 \% \text { CI })\end{array}$} \\
\hline & & $\operatorname{rs6827359}(\mathrm{C})$ & $\operatorname{rs12500837}(\mathrm{C})$ & rs9999653 (T) & H2 (CCT) & H4 (CTT) & H8 (TTT) & H7 (TTC) $^{\circ}$ \\
\hline \multirow[t]{2}{*}{ Fat } & $\mathrm{W} / \mathrm{M} \mathrm{vsW} / \mathrm{W}$ & $1.06(0.67-1.68)$ & $0.83(0.55-1.25)$ & $0.84(0.55-1.25)$ & $0.91(0.59-1.40)$ & $1.04(0.67-1.61)$ & $0.81(0.44-1.49)$ & $0.88(0.57-1.36)$ \\
\hline & $\mathrm{M} / \mathrm{M}$ vsW/W & $1.07(0.63-1.84)$ & $0.98(0.44-2.19)$ & $1.13(0.66-1.92)$ & $1.15(0.50-2.67)$ & $1.35(0.52-3.49)$ & $1.84(0.34-9.97)$ & $1.03(0.59-1.79)$ \\
\hline \multirow[t]{2}{*}{ Salt } & $\mathrm{W} / \mathrm{M}$ vsW/W & $1.21(0.76-1.93)$ & $1.05(0.69-1.60)$ & $1.22(0.74-2.02)$ & $1.14(0.73-1.80)$ & $1.23(0.78-1.94)$ & $0.87(0.49-1.56)$ & $0.97(0.62-1.54)$ \\
\hline & $\mathrm{M} / \mathrm{M}$ vsW/W & $1.12(0.65-1.94)$ & $0.85(0.39-1.88)$ & $1.24(0.72-2.13)$ & $0.96(0.40-2.30)$ & $1.15(0.50-2.65)$ & $2.99(0.28-32.52)$ & $0.85(0.49-1.47)$ \\
\hline \multirow[t]{2}{*}{ Sweet } & $\mathrm{W} / \mathrm{M}$ vsW/W & $1.06(0.69-1.63)$ & $1.00(0.68-1.46)$ & $1.11(0.70-1.77)$ & $1.03(0.69-1.54)$ & $1.21(0.81-1.82)$ & $1.13(0.66-1.95)$ & $0.84(0.56-1.25)$ \\
\hline & $\mathrm{M} / \mathrm{M} \mathrm{vsW} / \mathrm{W}$ & $1.24(0.75-2.04)$ & $0.82(0.40-1.68)$ & $1.34(0.81-2.20)$ & $1.11(0.48-2.57)$ & $1.59(0.71-3.56)$ & $1.87(0.47-7.41)$ & $0.79(0.47-1.32)$ \\
\hline \multirow[t]{2}{*}{ Flavour } & $\mathrm{W} / \mathrm{M}$ vsW/W & $1.26(0.82-1.96)$ & $0.87(0.59-1.29)$ & $1.20(0.74-1.93)$ & $0.77(0.51-1.16)$ & $0.93(0.61-1.42)$ & $0.94(0.56-1.59)$ & $1.42(0.94-2.13)$ \\
\hline & $\mathrm{M} / \mathrm{M}$ vsW/W & $0.86(0.52-1.42)$ & $0.84(0.41-1.75)$ & $0.83(0.50-1.37)$ & $0.89(0.38-2.08)$ & $1.07(0.47-2.41)$ & $0.88(0.16-4.80)$ & $1.08(0.64-1.84)$ \\
\hline \multirow[t]{2}{*}{ Umami } & $\mathrm{W} / \mathrm{M}$ vsW/W & $1.17(0.69-1.97)$ & $1.26(0.80-1.96)$ & $0.94(0.54-1.64)$ & $1.56(0.96-2.53)$ & $1.29(0.78-2.11)$ & $1.50(0.76-2.95)$ & $0.42(0.26-0.68) *$ \\
\hline & $\mathrm{M} / \mathrm{M} \mathrm{vsW} / \mathrm{W}$ & $2.57(1.43-4.61) *$ & $1.98(0.87-4.50)$ & $2.31(1.29-4.15)^{*}$ & $2.92(1.17-7.33)$ & $4.78(1.86-12.30) *$ & $1.00(0.18-5.70)$ & $0.43(0.24-0.78)$ \\
\hline
\end{tabular}

Bold: nominally significant associations; *significant also after FDR correction, including rare haplotypes (not shown); ${ }^{\circ}$ all other haplotypes as reference; $\uparrow$ for genotype analysis, heterozygotes or homozygotes for variant alleles (M) vs homozygotes for wild-type allele (W, ref); for haplotype analysis, subjects with $1(\mathrm{w} / \mathrm{M})$ or two $(\mathrm{M} / \mathrm{M})$ copies of a specific haplotypes versus subjects with the most frequent haplotype (TTC). Analyses adjusted for age, sex, country. 
Supplementary Table 2. Associations between Neuromedin U genotypes and taste thresholds in the IDEFICS children population.

\begin{tabular}{|c|c|c|c|c|c|c|c|c|}
\hline \multirow[b]{2}{*}{ Taste } & \multirow[b]{2}{*}{$\begin{array}{c}\text { Genotvpe or } \\
\text { haplotvpe } \\
\text { contrast } \dagger\end{array}$} & \multicolumn{3}{|c|}{$\begin{array}{c}\text { Genotypes } \\
(\text { beta } \pm \text { SE, } \boldsymbol{p})\end{array}$} & \multicolumn{4}{|c|}{$\begin{array}{c}\text { Haplotypes } \\
(\text { beta } \pm \text { SE, } \boldsymbol{p})\end{array}$} \\
\hline & & rs6827359 (C) & rs12500837 (C) & rs9999653 (T) & H2 (CCT) & H4 (CTT) & H8 (TTT) & H7 (TTC) $^{\circ}$ \\
\hline \multirow[t]{2}{*}{ Sweet } & $\mathrm{W} / \mathrm{M}$ vsW/W & $-0.35 \pm 1.11(0.75)$ & $-0.08 \pm 0.99(0.93)$ & $-1.43 \pm 1.17(0.22)$ & $-1.01 \pm 1.05(0.34)$ & $-0.83 \pm 1.02(0.41)$ & $-1.79 \pm 1.32(0.18)$ & $0.69 \pm 0.99(0.49)$ \\
\hline & $\mathrm{M} / \mathrm{M} \mathrm{vsW} / \mathrm{W}$ & $-0.68 \pm 1.30(0.60)$ & $0.03 \pm 1.87(0.99)$ & $-1.83 \pm 1.29(0.16)$ & $-0.28 \pm 2.09(0.89)$ & $-1.46 \pm 2.06(0.48)$ & $-1.97 \pm 1.99(0.32)$ & $1.48 \pm 1.33(0.26)$ \\
\hline \multirow[t]{2}{*}{ Salt } & $\mathrm{W} / \mathrm{M} \mathrm{vsW} / \mathrm{W}$ & $1.12 \pm 0.72(0.12)$ & $1.24 \pm 0.64(0.054)$ & $0.24 \pm 0.77(0.75)$ & $0.68 \pm 0.69(0.32)$ & $-0.10 \pm 0.70(0.88)$ & $-1.51 \pm 0.82(0.07)$ & $0.70 \pm 0.67(0.29)$ \\
\hline & $\mathrm{M} / \mathrm{M} \mathrm{vsW} / \mathrm{W}$ & $0.67 \pm 0.84(0.43)$ & $0.04 \pm 1.22(0.97)$ & $-0.34 \pm 0.84(0.69)$ & $0.00 \pm 1.24(1.00)$ & $-0.41 \pm 1.30(0.75)$ & $-3.25 \pm 1.68(0.053)$ & $0.02 \pm 0.86(0.98)$ \\
\hline \multirow[t]{2}{*}{ Bitter } & $\mathrm{W} / \mathrm{M} \mathrm{vsW} / \mathrm{W}$ & $-0.01 \pm 0.05(0.85)$ & $0.03 \pm 0.04(0.53)$ & $-0.01 \pm 0.05(0.84)$ & $0.01 \pm 0.05(0.80)$ & $-0.02 \pm 0.05(0.59)$ & $0.01 \pm 0.06(0.89)$ & $-0.01 \pm 0.05(0.90)$ \\
\hline & $\mathrm{M} / \mathrm{M} \mathrm{vsW} / \mathrm{W}$ & $-0.04 \pm 0.06(0.50)$ & $0.01 \pm 0.08(0.89)$ & $-0.04 \pm 0.06(0.53)$ & $-0.03 \pm 0.09(0.75)$ & $-0.07 \pm 0.08(0.37)$ & $0.27 \pm 0.18(0.13)$ & $0.00 \pm 0.06(0.95)$ \\
\hline \multirow[t]{2}{*}{ Umami } & $\mathrm{W} / \mathrm{M} \mathrm{vsW} / \mathrm{W}$ & $-0.50 \pm 0.32(0.12)$ & $0.14 \pm 0.29(0.61)$ & $-0.43 \pm 0.34(0.20)$ & $0.01 \pm 0.31(0.97)$ & $-0.32 \pm 0.31(0.30)$ & $-0.09 \pm 0.46(0.85)$ & $-0.35 \pm 0.30(0.25)$ \\
\hline & $\mathrm{M} / \mathrm{M}$ vsW/W & $-0.13 \pm 0.38(0.74)$ & $0.19 \pm 0.54(0.73)$ & $-0.29 \pm 0.37(0.43)$ & $0.00 \pm 0.57(0.99)$ & $-0.34 \pm 0.49(0.49)$ & $-0.22 \pm 1.17(0.85)$ & $0.28 \pm 0.39(0.47)$ \\
\hline
\end{tabular}

${ }^{\circ}$ All other haplotypes as reference; $\uparrow$ for genotype analysis, heterozygotes or homozygotes for variant alleles (M) vs homozygotes for wild-type allele (W, ref); for haplotype analysis, subjects with $1(\mathrm{w} / \mathrm{M})$ or two $(\mathrm{M} / \mathrm{M})$ copies of a specific haplotypes versus subjects with the most frequent haplotype (TTC). Analyses adjusted for age, sex, country. Lower detection threshold values indicate higher sensitivity for a specific tastant. 